\title{
MENINGKATKAN HARDSKILLS SISWA MELALUI PENERAPAN MODEL PEMBELAJARAN TEACHING FACTORY 6 LANGKAH
}

\author{
Tyan Risdiana ${ }^{1}$, Dadang Hidayat ${ }^{2}$, Amay Suherman $^{3}$ \\ Departemen Pendidikan Teknik Mesin FPTK UPI \\ Jl. Dr. Setiabudhi No. 207 Bandung 40154 \\ tyanrisdiana@gmail.com
}

\begin{abstract}
ABSTRAK
Tujuan penelitian ini adalah untuk mengetahui peningkatan kemampuan hardskills siswa sebelaum dan sesudah penggunaan model pembelajaran Teaching Factory 6 Langkah. Fokus penelitian pada kompetensi mengerjakan pesanan service ringan dan melakukan quality control. Objek dari penelitian ini adalah siswa kelas XI B SMK Negeri 1 Majalengka Kompetensi Keahlian Teknik Sepeda Motor. Penelitian ini dilakukan dengan menggunakan metode quasi experiment dengan desain one-group pretest-posttest design. Instrumen yang digunakan adalah tes unjuk kerja yang direkam pada lembar pengamatan atau observasi. Kemampuan hardskills siswa dalam mengerjakan pesanan service ringan dan melakukan quality control mengalami peningkatan setelah menggunakan model pembelajaranTeaching Factory 6 Langkah. Rata-rata peningkatan mengerjakan pesanan service ringan dan melakukan quality control berkategori sedang dengan nilai $n$-gain masing-masing kegiatan tersebut adalah 0,681 dan 0,582 .
\end{abstract}

Kata kunci: teaching factory 6 langkah, kompetensi, quality control.

\section{PENDAHULUAN}

Hasil belajar siswa SMK Negeri 1 Majalengka pada Kompetensi Keahlian Teknik Sepeda Motor masih banyak yang di bawah Kriteria Ketuntasan Minimal (KKM) yang telah ditetapkan. Hasil belajar siswa dapat dilihat dari nilai hasil uji kompetensi yang dilaksanakan pada setiap akhir semester. Nilai yang diperoleh siswa pada standar kompetensi memperbaiki kerusakan sistem bahan bakar bensin masih menunjukkan bahwa masih banyak siswa yang memiliki nilai di bawah KKM. Untuk kelas XI TSM A berjumlah 31 siswa atau 94\% dan kelas XI TSM B berjumlah 27 siswa atau 79\%. Keberhasilan seorang pengajar akan terjamin, apabila pengajar itu dapat mengajak para muridnya mengerti suatu masalah melalui semua tahap proses belajar (Sagala, 2013). Pada proses pembelajaran guru harus dapat menggunakan model-model pembelajaran agar keberhasilan pembelajaran dapat terjamin dan berhasil sesuai yang direncanakan.

\footnotetext{
${ }^{1}$ Mahasiswa Departemen Pendidikan Teknik Mesin FPTK UPI

${ }^{2}$ Dosen Departemen Pendidikan Teknik Mesin FPTK UPI

${ }^{3}$ Dosen Departemen Pendidikan Teknik Mesin FPTK UPI
} 
Hasil belajar (kompetensi) siswa dipengaruhi oleh dua faktor, yaitu (1) faktor internal seperti kesehatan, minat, bakat, motivasi dan kematangan. (2) faktor eksternal seperti keluarga, sekolah atau lingkungan pembelajaran. Berkaitan dengan aspek pembelajaran, aspek yang mempengaruhi hasil belajar salah satunya adalah metode pembelajaran yang digunakan (Slameto, 2010). Metode pembelajaran yang kurang baik akan memengaruhi belajar siswa yang kurang baik dan berdampak pada hasil belajar yang kurang baik pula.

Mengajar bagi seorang guru bukan tugas yang ringan. Guru harus menjalankan prinsipprinsip dalam mengajar agar proses pembelajaran dapat dilaksanakan seefektif mungkin. Salah satu prinsip dalam mengajar yaitu adalah repetisi atau pengulangan. Repetisi atau pengulangan merupakan hal yang sangat penting dalam proses pembelajaran. Ingatan siswa tidak setia, maka perlu dibantu dengan mengulangi pelajaran yang sedang dijelaskan. Pelajaran yang diulang memberikan tanggapan yang jelas dan tidak mudah dilupakan. Berdasarkan uraian di atas, jelaslah bahwa metode yang digunakan dalam pembelajaran akan memengaruhi hasil belajar siswa. Metode mengajar yang baik kurang baik akan mempengaruhi hasil belajar siswa.

Inovasi dalam kegiatan pembelajaran perlu dilakukan untuk meningkatkan pencapaian kompetensi siswa, salah satunya adalah dengan menerapkan model pembelajaran Teaching Factory 6 Langkah (Model TF-6M). Model pembelajaran ini merupakan model pembelajaran yang dikembangkan oleh Dadang Hidayat Martawijaya dalam penulisan disertasinya. Model pembelajaran ini akan memungkinkan mengubah suasana sekolah menjadi layaknya suasana di industri. Guru berperan sebagai asesor dan konsultan, sedangkan siswa berperan sebagai pekerja layaknya di industri sesuai tugas dan tanggung jawabnya masing-masing. Melalui penerapan model pembelajaran Model TF-6M) siswa akan mendapatkan pengalaman bagaimana bekerja di dunia industri yang sebenarnya. Pengalaman yang diperoleh salah satunya berkaitan dengan kemampuan hardskills. Melalui penerapan model pembelajaran ini diharapkan terjadi peningkatan kemampuan hardskills yang dimiliki oleh siswa, serta siswa lebih siap untuk memasuki dunia kerja.

Hardskills berkaitan dengan kemampuan teknis atau administrasi seseorang yang berkaitan dengan pekerjaannya. Hardskills adalah kemampuan teknis yang dimiliki oleh individu. Hardskills merupakan keterampilan yang diperoleh melalui pendidikan atau pembelajaran dan aplikasi praktik (Rao, 2010). Inovasi model dalam penyampaian pembelajaran saat ini banyak dilakukan. Hal ini dilakukan dalam upaya meningkatkan kompetensi siswa. Salah satu 
perkembangan dari model penyampaian pembelajaran adalah dengan pengembangan model pembelajaran. Departemen Pendidikan Nasional telah menggulirkan kebijakan untuk menerapkan konsep teaching factory untuk konsep pembelajaran siswa di SMK.

Model TF-6M bertujuan meningkatkan kompetensi siswa dalam mata pelajaran produktif, dengan menciptakan hubungan sosial dalam bentuk berkomunikasi, dan bekerja sebagai pekerja dalam iklim atau suasana industri dalam suatu block waktu di sekolah. Langkah 1, berperan sebagai pekerja, siswa menerima pemberi pesanan dengan berkomunikasi yang baik, dengan memperhatikan intonasi, mimik muka dan body language. Langkah 2, menganalisis pesanan: membaca work pesanan, menentukan alat dan bahan, waktu kerja, harga dan tentang keselamatan kerja. Pekerja berkonsultasi dengan konsultan. Langkah 3, hasil analisis pesanan, dengan penuh keyakinan pekerja menyatakan kesiapan mengerjakan pesanan dengan tutur kata yang baik. Langkah 4, mengerjakan pesanan dengan menerapkan keselamatan kerja, melakukan persiapan kerja, langkah kerja sesuai SOP, menilai hasil kerja dan menghitung waktu kerja, dan berkonsultasi dengan konsultan. Langkah 5, melakukan quality control, mencocokan spesifikasi pabrik, memastikan komponen dan sistem berfungsi dengsn baik dan berkonsultasi dengan konsultan. Langkah 6, bertutur kata dengan baik dalam menyerahkan hasil kerja, meminta tanggapan pemberi pesanan tentang hasil kerja, berusaha membina komunikasi yang baik dengan pemberi pesanan.

\section{METODE PENELITIAN}

Penelitian ini dilakukan di SMK Negeri 1 Majalengka. Aspek yang diteliti dalam penelitian ini adalah kemampuan hardskills siswa XI TSM B dalam mengerjakan pesanan service ringan dan melakukan quality control sebelum dan sesudah mendapatkan pembelajaran Model TF-6M. Penelitian ini adalah penelitian eksperiman dengan jenis one group pretest posttest. Data yang diperoleh dari hasil pretest dan posttest kemudian dianalisis dengan menggunakan program SPSS. Uji statistik yang digunakan adalah uji t untuk dua kelas sampel yang berpasangan. Kemudian, untuk mengetahui kategori peningkatan hardskills yang dicapai siswa digunakan nilai $N$-gain. 


\section{HASIL PENELITIAN}

Berdasarkan hasil analisis data, rata-rata n-gain yang dicapai oleh kelas dalam MOSR sebanyak lima kali dengan pembelajaran Model TF-6M adalah sebesar 0,681 dan rata-rata peningkatan tersebut berada pada kategori sedang. Adapun grafik rata-rata $n$-gain keseluruhan siswa dalam MOSR diperoleh rata-rata $n$-gain yang dicapai oleh kelas dalam MQC sebanyak lima kali dengan pembelajaran Model TF-6M adalah sebesar 0,58 dan rata-rata peningkatan tersebut berada pada kategori sedang.

Uji hipotesis bertujuan untuk menguji apakah hipotesis yang diajukan dapat diterima atau ditolak, adapun hipotesis yang diuji adalah hipotesis nol $\left(\mathrm{H}_{0}\right)$. Berdasarkan hasil interpretasi dinyatakan bahwa $\mathrm{H}_{0}$ ditolak atau dengan kata lain $\mathrm{H}_{\mathrm{a}}$ diterima, artinya terjadi peningkatan kemampuan hardskills yang signifikan dalam melakukan pekerjaan service ringan sesudah diterapkan Model TF-6M. Skor rata-rata hardskills yang diperoleh siswa meningkat setelah diterapkan Model TF-6M. Hasil uji hipotesis melakukan quality control hasil interpretsai Tabel, dinyatakan bahwa $\mathrm{H}_{0}$ ditolak atau de-ngan kata lain $\mathrm{H}_{\mathrm{a}}$ diterima, artinya terjadi peningkatan kemampuan hardskills yang signifikan dalam melakukan quality control dan skor rata-rata hardskills meningkat sesudah diterapkan Model TF-6M.

\section{PEMBAHASAN}

Model TF-6M terdiri dari 6 langkah kerja yang harus dilakukan siswa dalam proses pembelajaran, namun langkah yang diteliti dalam penelitian ini adalah langkah mengerjakan pesanan dan melakukan quality control karena bentuk kegiatan dalam langkah tersebutlah yang mengGambarkan kegiatan hardskills dalam ranah psikomotor. Langkah mengerjakan pesanan dalam penelitian ini terdiri dari dua jenis kegiatan, yaitu persiapan kerja dan proses kerja. Skor rata-rata pretest kemampuan hardskills pada aspek persiapan kerja adalah sebesar 5,47 dari skor maksimal 12 dan posstest adalah sebesar 11,85 dari skor maksimal 12, sedangkan dalam kegiatan proses kerja siswa mendapatkan rata-rata skor pretest sebesar 31,12 dari skor maksimal 72 dan rata-rata posttest sebesar 70,26 dari skor maksimal 72. Skor tersebut mengGambarkan kemampuan hardskills siswa dalam melakukan persiapan kerja dan proses kerja pada saat pretest dan posttest. 
Kemampuan hardskills siswa dalam kegiatan persiapan kerja dan proses kerja sebelum diterapkan Model TF-6M jauh lebih rendah dari skor maksimal yang harus dicapai. Siswa pada awalnya terlihat kebingungan dengan apa yang harus mereka lakukan dalam kegiatan persiapan kerja, terlihat dari banyak dan seringnya siswa yang bertanya kepada guru (konselor) terkait apa yang harus mereka siapkan. Kemampuan awal siswa dalam proses kerja juga jauh di bawah kemampuan ideal yang diharapkan. Terlihat pada saat siswa melakukan proses kerja, mereka banyak bertanya kepada temanya terkait apa yang harus mereka lakukan. Mereka terlihat tidak percaya diri dalam melakukan pekerjaan. Pekerjaan yang mereka lakukan pun belum memenuhi ketentuan, hal ini dibuktikan dengan sepeda motor yang harus di-service ulang oleh seorang mekanik sekolah.

Waktu yang dibutuhkan oleh siswa pun dalam melakukan pekerjaan melebihi dari waktu ideal yang telah dijanjikan. Setelah siswa mendapatkan pengalaman kerja melalui kegiatan Model TF-6M, terlihat kemampuan hardskills siswa meningkat secara signifikan. Rata-rata skor yang dicapai siswa pada saat posttest hampir mendekati skor maksimal yang diharapkan. Sepeda motor yang di-service oleh siswa tidak lagi harus di-service ulang oleh mekanik. Waktu kerja yang digunakan siswa lebih baik dari waktu kerja yang telah mereka tetapkan sendiri. Pekerjaan selesai tepat pada waktunya bahkan ada yang lebih cepat dengan hasil kerja yang baik.

Langkah selanjutnya adalah melakukan quality control, pada langkah ini kemampuan awal siswa dalam melakukan quality control masih rendah, terlihat dari perolehan skor rata-rata yang hanya sebesar 6,23 dari skor yang diharapkan sebesar 15. Ada beberapa siswa yang bahkan tidak melakukan quality control terhadap pekerjaan yang mereka lakukan sendiri, ketika ditanya alasannya mereka menjawab karena tidak tahu apa yang dimaksud dengan quality control. Ada beberapa siswa yang mengetahui apa yang dimaksud dengan quality control namun mereka pun masih mengalami kesulitan karena tidak mengetahui standar spesifikasi kendaraan yang telah ditetapkan. Setelah Model TF-6M diterapkan, kemampuan siswa dalam melakukan quality control jauh lebih baik jika dibanding dengan kemampuan awalnya, terlihat dari perolehan skor rata-rata posttest sebesar 12,94 dari skor maksimal sebesar 15. Siswa semakin yakin dan percaya diri dengan hasil pekerjaannya.

Kemampuan hardskills siswa dalam mengerjakan pesanan dan melakukan quality control meningkat seiring bertambahnya pengalaman yang mereka dapatkan melalui pembelajaran Model TF-6M. Kemampuan hardskills siswa dalam mengerjakan pesanan dan melakukan quality 
control secara umum dapat dikatakan bergerak linier naik semenjak diterapkannya Model TF-6M sampai dilaksanakannya posttest. Peningkatan kemampuan hardskills dalam mengerjakan pesananservice ringan berada pada kategori sedang dengan nilai $n$-gain sebesar 0,681, begitupun dalam melakukan quality control peningkatannya berada pada kategori sedang dengan nilai $n$ gain sebesar 0,582 .

Peningkatan kemampuan hardskills yang dicapai siswa tentunya dipengaruhi oleh berbagai faktor. Peningkatan kemampuan hardskills siswa tersebut diperoleh dari praktik yang dilakukan berulang-ulang selama proses pembelajaran dengan Model TF-6M. Kemampuan hardskills diperoleh melalui aplikasi praktik (Bhatnagar, 2012). Tentunya aplikasi praktik pun tidak akan berdampak efektif jika hanya dilakukan sekali. Perlu dilakukan pengulangan yang terus menerus agar kemampuan yang telah diperoleh tidak mudah hilang. Selain faktor tersebut, pemilihan dan penggunaan model pembelajaran pun sangat menentukan hasil belajar siswa. Salah satu faktor yang dapat memengaruhi hasil belajara siswa adalah penggunaan metode pembelajaran (Slameto (2010).

Baik atau buruknya metode pembelajaran yang digunakan akan berdampak pada baik dan buruknya pencapaian hasil belajar siswa. Penggunaan metode pembelajran pun tidak akan efektif dalam meningkatkan kemampuan hardskills siswa apabila tidak memperhatikan prinsip-prinsip pembelajaran yang salah satunya adalah adanya repetisi atau pengulangan. Telah dikatakan sebelumnya bahwa efektifnya Model TF-6M dalam meningkatkan kemampuan hardskills siswa dikarenakan model tersebut memberikan pengalaman praktik yang berulang-ulang kepada siswanya, sehingga pengalaman yang telah didapatkan tidak mudah dilupakan. Pelajaran yang diulang memberikan tanggapan yang jelas dan tidak mudah dilupakan (Slameto, 2010).

Model TF-6M mampu memberikan pengalaman yang nyata kepada siswanya. Artinya Model TF-6M mampu memberikan gambaran yang sesungguhnya bagaimana seorang mekanik ketika bekerja memecahkan masalah yang terkait dengan pekerjaannya di dunia usaha. Pengalaman yang diperoleh siswa melalui Model TF-6M dalam mengerjakan pesanan dan melakukan quality control mampu meningkatkan kemampuan hardskills yang dimiliki siswa. Kemampuan psikomotor siswa dapat berkembang akibat adanya pengalaman, yang selanjutnya pengalaman tersebut digunakan untuk melakukan keterampilan yang lebih komplek.

Model TF-6M mampu memberikan pengalaman bagaimana seorang mekanik bekerja di dunia usaha yang sesungguhnya, sehingga memberikan dampak positif kepada siswa. Siswa lebih 
semangat dan disiplin dalam mengikuti proses pembelajaran, hal ini terlihat dari jam kedatangan siswa yang lebih awal dari yang telah ditetapkan. Kehadiran siswa dalam proses pembelajaran juga lebih baik jika dibanding dengan sebelum diterapkan Model TF-6M. Kehadiran siswa selama diterapkan Model TF-6M adalah 100\%.

Masalah yang dihadirkan melalui Model TF-6M terbukti mampu meningkatkan hardskills siswa dalam mengerjakan pesanan service ringan dan melakukan quality control. Hal ini terlihat dari kondisi siswa ketika dilakukan pengambilan data awal (pretest) terlihat bingung dalam mengerjakan pesanan service ringan dan melakukan quality control. Seiring bertambahnya pengalaman yang diperoleh siswa, kemampuan hardskills siswa dalam mengerjakan pesanan service ringan dan melakukan quality control pun semakin membaik. Intelektual berkembang ketika individu mengahadapi pengalaman baru yang membingungkan dan ketika mereka berusaha mengatasi diskrepansi yang ditimbulkan oleh pengalaman-pengalaman ini (Sugiyanto, 2010).

Masalah yang dihadirkan melalui Model TF-6M mampu membuat siswa lebih mandiri dan percaya diri dalam melakukan pekerjaannya, siswa tidak lagi bertanya dan meminta bantuan kepada temannya dalam melakukan pekerjaan service ringan. Berdasarkan pemaparan tersebut, tampak bahwa proses pembelajaran pada Model TF-6M berpengaruh positif pada faktor siswa yang meliputi kedisiplinan dan semangatsiswa dalam mengikuti proses pembelajaran dan juga memberikan rasa percaya diri sehingga siswa lebih mandiri dalam melaksanakan pekerjaannya.

Peningkatan kemampuan hardskills tersebut ber-dampak juga pada kecepatan siswa dalam melakukan pekerjaan service ringan. Semakin sering siswa melakukan proses pekerjaan service ringan maka semakin sedikit pula waktu kerja yang dibutuhkan oleh siswa. Hal tersebut akan menjadi nilai tambah tersendiri bagi siswa yang akan berguna ketika siswa tersebut memasuki dunia usaha. Siswa yang telah memiliki pengalaman kerja di sekolahnya tidak akan memerlukan waktu yang lama untuk beradaptasi ketika dia telah memasuki dunia usaha.

Model TF-6M mampu meningkatkan hasil belajar siswa pada ranah psikomotor atau yang dalam penelitian ini disebut dengan kemampuan hardskills. Model TF-6M mampu meningkatkan kompetensi siswa dalam bidang pemesinan (Rusman, 2012). Model TF-6M mampu meningkatkan hasil belajar siswa pada ranah psikomotor (hardskills) dalam bidang jasa pelayanan. Telah dibuktikan melalui uji hipotesis yang menyatakan bahwa terjadi peningkatan hardskills yang signifikan dalam mengerjakan pesanan service ringan dan melakukan quality 
control antara sebelum dan sesudah diterapkan Model TF-6M. Sehingga model ini bisa dijadikan acuan oleh sekolah lain dalam memilih model pembelajaran yang akan digunakan.

\section{KESIMPULAN}

Kesimpulan dari penelitian ini adalah terjadi peningkatan kemampuan hardskills, mengerjakan pesanan service ringan dan melakukan quality control yang dimiliki siswa penerapan model pembelajaran TF-6M. Rata-rata peningkatan kemampuan hardskills siswa dalam mengerjakan pesanan service ringan berkategori sedang. Rata-rata peningkatan kemampuan hardskills siswa dalam melakukan quality control berkategori sedang.

\section{DAFTAR PUSTAKA}

Bhatnagar, N. (2012). Effective Communication and Soft Skills. New Delhi: Dorling Kindersley.

Rao, M.S. (2010). Soft Skills Enchancing Employability Connecting Campus with Corporate. New Delhi: I.K. International Publishing House Pvt. Ltd.

Sagala, S. (2013). Konsep dan Makna Pembelajaran. Bandung: Alfabeta

Slameto. (2010). Belajar dan Faktor-Faktor Yang Mempengaruhinya. Jakarta: Rineka Cipta.

Sugiyanto. (2010). Model-Model Pembelajaran Inovatif. Surakarta: Yuma Pustaka.

Rusman. (2012). Model-Model Pembelajaran Mengembangkan Profesionalisme Guru. Jakarta: Rajawali Pers. 